\title{
EL COMPENDIO DE HISTORIA DE COLOMBIA DE HENAO Y ARRUBLA Y LA DIFUSIÓN DEL IMAGINARIO NACIONAL A COMIENZOS DEL SIGLO XX
}

\author{
ALEXIS V. PINILLA DÍAZ \\ Universidad Pedagógica Nacional
}

\begin{abstract}
Resumen
El Compendio de historia de Colombia de Henao y Arrubla y la difusión del imaginario nacional a comienzos de siglo $X X$.
\end{abstract}

En el presente artículo se hace una reflexión en torno a los fines sociales que le fueron otorgados a la educación a principios del siglo $\mathrm{XX}$, orientados a la constitución de determinado ideal de ciudadanía y a la consolidación del imaginario nacional. Para tal efecto, se hace referencia a los planes de estudios de las primeras décadas y a los textos escolares utilizados para la enseñanza de la historia que, sin lugar a dudas, se constituyó en una de las asignaturas de mayor relevancia para la promoción del imaginario nacionalista. En la parte final se alude al texto de Henao y Arrubla, entendiendo que éste material fue uno de los que más circulación y difusión tuvieron en nuestro contexto escolar.

\section{Palabras clave}

Identidad nacional, ciudadanía, cultura política, educación, textos escolares.

\section{Abstract}

In this article a reflection around the social goals that were granted to the education at the beginning of the $X X^{\text {th }}$ century is made, these goals were guided to the constitution of a certain citizenship ideal and to the consolidation of the national imaginary. In order to do this reflection reference is made to the curricula of the first decades and the school texts used for the teaching of history that, without any doubt, constituted in one of the more relevant subjects for the promotion of the national imaginary. In the final part the text of Henao and Arrubla is considered, because this material had a the broadest circulation and diffusion in our school.

\section{Key words}

National identity, citizenship, political culture, education, school texts. 


\title{
EL COMPENDIO DE HISTORIA DE COLOMBIA DE HENAO Y ARRUBLA Y LA DIFUSIÓN DEL IMAGINARIO NACIONAL A COMIENZOS DEL SIGLO XX ${ }^{55}$ *
}

\author{
ALEXIS V. PINILLA DÍAZ ${ }^{56}$ \\ Universidad Pedagógica Nacional
}

\section{Presentación}

Uno de los temas que ha cobrado importancia como producto de los procesos de globalización cultural en los últimos años del siglo $X X$, ha sido la pregunta por la identidad nacional. ¿Qué queda de ella en un mundo globalizado?, ¿es posible sostener la idea de identidades nacionales tal y como fueron concebidas hace un siglo? Teniendo en cuenta estos interrogantes, el interés del presente artículo se centra en indagar por los soportes, las fuentes, de la identidad nacional colombiana que se produjeron en la coyuntura de la primera década del siglo XX.

Así mismo, se busca mostrar el papel que cumplió la educación en dicho proceso, entendiendo que a través de ella se transmiten y reconfiguran elementos de cultura política, a partir del análisis de un texto escolar de amplia circulación en el país, como lo fue el Compendio de historia de Colombia de Henao y Arrubla. Para tal efecto, en la primera parte se hará mención a los fines de la educación a comienzos del siglo XX; en la segunda se hará una breve mención a los planes de estudio y el lugar de la historia en los mismos; y, la parte final, se dedica al análisis de los imaginarios sobre identidad nacional que se propusieron y circularon en el texto de Henao y Arrubla.

\section{Fines sociales de la educación a principios del siglo $\mathrm{XX}$}

En términos generales, podríamos anotar que las estrategias básicas esgrimidas en la política educativa de principios del siglo $\mathrm{XX}$ se relacionan con tres aspectos específicos: primero, fortalecer la capacidad práctica y la orientación al trabajo de los individuos; segundo, reconocer a Dios como fuente de todo poder y, por último, fomentar el sentimiento nacionalista y patriótico en los niños y jóvenes con miras a consolidar un proyecto nacional. Si bien existieron algunas reformas a esta legislación educativa, podríamos señalar que las estrategias descritas impregnaron el sistema educativo durante las tres primeras décadas del siglo XX. A continuación, se señalan algunas particularidades de los fines educativos en la coyuntura de fines del siglo XIX e inicios del $\mathrm{XX}$.

Para finales del siglo XIX, el sistema educativo estaba organizado de acuerdo a lo dispuesto en el Decreto 349 de 1892, en cuyo artículo $1^{\circ}$ se leía: "La Instrucción Pública se divide en Departamental y Nacional. De acuerdo con lo dispuesto en el artículo 185 de la Constitución y por la Ley 89 de 1892, es Instrucción Pública Departamental la primaria o de primeras letras. Por Instrucción Nacional se entiende la secundaria y la profesional"

\footnotetext{
55 Este artículo fue resultado de la pasantía de investigación durante el año 2002, en el programa de Jóvenes Investigadores de Colciencias.

* Artículo recibido el 5 de septiembre de 2003 y arbitrado el 22 de septiembre de 2003.

${ }^{56}$ Magíster en Historia de la Educación. Integrante del grupo de investigación Educación y Cultura política, de la Universidad Pedagógica Nacional. Correo electrónico: alepinilla@hotmail.com
} 
57. Esta Ley 89 y el Decreto 349 de 1892, son conocidos en la historia de la educación colombiana como el Plan Zerda, el cual buscó,

[...] trazar normas de organización nacional para la enseñanza e imponer un sistema de educación nacionalmente unificado 'hasta donde sea posible', como de manera explícita lo reconocía el propio plan, pues a pesar de que la Constitución del 86 hubiera sometido formalmente a los antiguos estados soberanos, por muchos años más las estructuras locales y regionales de poder, que eran las que efectivamente marcaban de manera cotidiana mucho del carácter de las prácticas educativas, continuaban funcionando como los centros básicos de decisión ${ }^{58}$.

En 1894, el mismo Ministro de Instrucción; Liborio Zerda, reglamentó el funcionamiento de la escuela primaria anotando que el medio pedagógico general que debía emplearse para la enseñanza era la intuición y que, por ende, se necesitaban, "pocas palabras, salvo en las narraciones. Nada de definiciones" ${ }^{59}$. En esta perspectiva se propuso que el método a utilizar en la enseñanza de las diferentes materias era el de "Pestalozzi perfeccionado", prohibiendo toda enseñanza "fundada en el ejercicio exclusivo y servil de la memoria" 60 . En torno a estas orientaciones pedagógicas, anotemos que el ideario pestalozziano había ingresado al país desde mediados del siglo XIX, en el gobierno de Mariano Ospina Rodríguez, como un recurso para mejorar las propuestas pedagógicas con las cuales se venía trabajando, producto de la utilización de las ideas lancasterianas. Para finales del siglo XIX, además de entender a Pestalozzi como una vía de renovación pedagógica, se le atribuyó un componente de control, político y social que sería de utilidad para el proceso de construcción de la nación moderna. Para Sáenz, Saldarriaga y Ospina,

[...] al menos desde 1870, el memorismo y el verbalismo se habían convertido en los grandes problemas pedagógicos que entorpecían la instrucción de los niños colombianos [...] el gran reto para los instruccionistas y sus métodos modernos era desterrar la repetición, ganar por vías positivas la atención de los niños, como única vía para desarrollar su entendimiento. Era efectuar, como proyecto político y de gobierno social, la profecía del ilustrado Pestalozzi: hacer de la enseñanza primaria popular, la 'posibilidad del mejoramiento de la especie humana'61.

La preocupación del reglamento de la escuela primaria no giró exclusivamente en torno al método pedagógico que los maestros debían seguir ${ }^{62}$. También se hizo énfasis en el fortalecimiento de la moral y la salud física de los niños, aludiendo a que la nación requería de individuos con cuerpos y mentes fuertes capaces de articularse a las exigencias del medio a través de la realización de tareas y oficios prácticos. En el artículo 77 del reglamento elaborado por Liborio Zerda, atinente a la educación física, se anotó que "no debe admitirse en la escuela niño alguno de constitución excesivamente débil o con tendencia marcada a enfermarse" $"$. Así mismo, se empezó a hacer énfasis en la

57 Tomado de: GALELGo CARDONA, Juan, Pensumes colombianos de Enseñanza Secundaria, 1887 a 1955, Medellín, s. e., 1955.

58 SILVA, Renán, "La educación en Colombia". 1880 - 1930", en Nueva Historia de Colombia, Bogotá, Planeta, 1998, tomo IV, p. 72.

${ }^{59}$ Reglamento para las escuelas primarias. $1^{\circ}$ de enero de 1894. Artículo $6^{\circ}$.

${ }^{60}$ Ibíd., Artículo 19.

61 SÁENZ, Javier; SALDARRIAGA, Oscar y OSPINA, Armando, Mirar la infancia: pedagogía, moral y modernidad en Colombia, 1903 - 1946, Bogotá, Colciencias, Ediciones Foro, Ediciones Uniandes, Editorial Universidad de Antioquia, 1997, Vol. 1., p 19.

62 Para profundizar en torno al componente pedagógico de los textos escolares en esta coyuntura ver: HERRERA, Martha; PINILLA, Alexis y SUAZA, Luz Marina, "Perspectivas pedagógicas de los textos escolares de ciencias sociales en la primera mitad del siglo XX", en Pedagogía y Saberes, $\mathrm{N}^{\circ} 17$, Bogotá, Universidad Pedagógica Nacional, 2002.

${ }^{63}$ Reglamento para las escuelas primarias. $1^{\circ}$ de enero de 1894. 
necesidad de consolidar una educación práctica, que condujese al posterior desarrollo de la educación técnica e industrial ${ }^{64}$.

En el proyecto político y educativo definido por las elites criollas a finales del siglo XIX, y principalmente a partir de la Constitución Política de 1886, se hacía una clara demarcación de los límites entre las fracciones de clase. La educación debería tratar de conservar estos límites orientando la formación de las elites dentro de las artes y las disciplinas liberales y capacitando a los sectores populares para el trabajo técnico y práctico. En esta perspectiva, si bien se planteó la necesidad de crear un sistema educativo nacional, era difícil pensar en una escuela homogénea, en la medida en que la enseñanza debía responder a fines diversos y opuestos. Sobre este aspecto, en 1897, Eugenio González Mutis, anotó lo siguiente:

Téngase también en cuenta que la igualdad en la instrucción, cuando ésta no va cimentada en los principios cristianos, pone más de resalto la desigualdad de las condiciones. Si el hijo de padres sencillos e ignorantes se ve, por gracia del Estado, en contacto con los que pertenecen a la clase distinguida de la sociedad y adquiere conjuntamente con ellos los mismos conocimientos, llegará, por fuerza, a avergonzarse de su familia y de su origen; los odios de raza y las más feroces pasiones se apoderarán de su alma, y en lugar de un ciudadano útil a su patria, habrá en él un enemigo del orden y partidario de la Revolución. Peores resultados produjo todavía la enseñanza obligatoria tratándose de las mujeres, pues imprudentemente recibían una instrucción para la cual encontraban humillantes todos los oficios que entre nosotros pueden desempañar, y como no era mucha la virtud que se les infundía, al poco de salir de la escuela daban al traste con el pudor y se entregaban a la desvergüenza ${ }^{65}$.

Del anterior comentario podemos inferir que para los sectores hegemónicos de la sociedad colombiana resultaba contraproducente una enseñanza homogénea, ya que ésta cuestionaría la legitimidad del orden social reinante e iría en contra de los propios intereses de las elites. A principios del siglo XX, la estrategia educativa consistió, entonces, en fragmentar la enseñanza; es decir, en dar un estilo de educación a cada grupo social de acuerdo a sus orígenes sociales y culturales y a sus contextos de socialización. Además de la división en torno a la educación destinada a las clases populares y a las elites criollas, era evidente una brecha entre la educación rural y la educación urbana. Los habitantes del campo estaban en una situación desventajosa frente a los de la ciudad e incluso, en esta última se presentaba marcadas diferenciaciones entre los sectores populares y de elite.

No obstante, es conveniente anotar que la organización de la educación a principios del siglo $\mathrm{XX}$, generó tensiones dentro de las mismas elites nacionales y en algunos sectores de la dirección educativa nacional. Esta tensión se puede ver en un análisis sobre la educación primaria realizado por José Miguel Rosales, vicerrector de la Escuela Nacional de Comercio, divulgado en el año de 1900. En el documento elaborado por Rosales encontramos lo siguiente:

[...] en nuestra tierra la escuela primaria, a causa de su pésima organización pedagógica, ni educa, ni instruye. En la administración escolar predomina la anarquía, no hay uniformidad en los programas, los maestros carecen de preparación suficiente, los edificios escolares son inadecuados y no hay útiles de ninguna clase, los métodos son defectuosos y los inspectores, tanto locales como provinciales, con rarísimas excepciones, no son personas técnicas ni tienen interés por el Ramo, ni saben cumplir con sus deberes. Por último, el programa abarca seis años, pero los niños no asisten

${ }^{64}$ SAFFORD, Frank, El ideal de lo práctico, Bogotá, Empresa Editorial Universidad Nacional, El Áncora Editores, 1989.

${ }^{65}$ GONZÁLEZ MUTIS, Eugenio, La instrucción pública en Colombia, Bogotá, Imprenta Nacional, 1897, p. 71. 
sino dos o tres años a lo más en las escuelas urbanas, y en las rurales apenas completan el primer año de estudios ${ }^{66}$.

De esta cita podemos resaltar algunos elementos centrales sobre la problemática de la educación primaria. En primer lugar, se hace alusión a la anarquía que reina en la educación, argumentando que ésta es producto de la no uniformidad en los programas. Al parecer, la tensión en este aspecto giraba en cómo ofrecer una enseñanza uniforme pero que mantuviese las diferencias socioeconómicas y, además, ayudara a superar la fragmentación del país producto de la federalización ocurrida a partir de 1863. En segundo término, es interesante ver la poca capacidad de cobertura del sistema educativo y el alto índice de deserción en las poblaciones que accedían a la educación. Este hecho cuestiona, incluso, el impacto que pudiese tener la enseñanza institucional en la construcción del proyecto nacional planteado por las elites. Por último, resulta significativa la observación sobre el desdeño con que se trataba el tema educativo por parte de los funcionarios del Ministerio de Instrucción. Quizás fueron estos problemas, entre otros más, los que motivaron la reforma educacionista de principios del siglo XX.

A partir de 1903, con la promulgación de la ley 39, emergió un marco normativo para la instrucción pública en Colombia. Uno de los más significativos principios que inspiró este nuevo código educativo está relacionado con la necesidad de que la educación contribuyera, de manera efectiva, al desarrollo industrial del país a través de la formación de personas capacitadas para las actividades prácticas. En la exposición de motivos de la Ley 39 de 1903 el Ministro de Instrucción Pública, Antonio José Uribe, anotó que todo el sistema educativo colombiano debía propender por el fortalecimiento de una educación que capacitara a los individuos para el trabajo. Según el ministro,

\begin{abstract}
En nuestro vicioso sistema de educación se encuentra principalmente el origen de nuestro singular atraso industrial, y en mucha parte el de las guerras civiles. El desequilibrio social que se produce con la falta de obreros hábiles y con el aumento creciente de letrados inútiles, es causa del malestar en que vivimos, de la penuria en que nos hallamos y de la falsa noción de la vida que aquí se tiene, por lo cual todos nos encaminamos a las agitaciones políticas que, periódicamente, se desatan en luchas armadas [...] Si ante la dolorosa experiencia de lo que ha ocurrido, no hacemos voto formal de variar de rumbo, ya podemos estar seguros de que de aquella causa, como de fuente envenenada, seguirán brotando todos nuestros males, y de que, en cumplimiento de la inexorable ley de la selección de las razas, la nuestra, empeñada en vivir dentro de la atmósfera de la especulación política, tiene que desaparecer, por la concurrencia y la lucha de organismos más fuertes, que se robustecen con la savia del trabajo y de la industria. Es necesario convertir la República entera en un inmenso taller, pues sólo con el trabajo podremos curar las profundas dolencias que afligen a la sociedad colombiana ${ }^{67}$.
\end{abstract}

Además del reclamo por una educación que fortaleciera la formación práctica de los individuos, encontramos varios elementos de análisis interesantes en las palabras del ministro. En primer lugar, es importante subrayar la responsabilidad que se le otorga a la educación, no sólo en el atraso económico del país, sino, además, en el estado de la situación política y social, aludiendo a que en el sistema educativo se encuentran las causas de las numerosas guerras civiles del siglo XIX. En segundo lugar, es evidente el carácter de darwinismo social de las apreciaciones del ministro, para quien la educación estaba contribuyendo a la formación de una raza débil destinada a desaparecer por la inexorable 'ley de la selección de las razas'. Por último, resulta significativo el hecho de que se quiera convertir a la nación en un 'inmenso taller' tratando de seguir el rumbo

\footnotetext{
${ }^{66}$ ROSALES, José Miguel (Vicerrector de la Escuela Nacional de Comercio), La reforma de la instrucción primaria oficial en Colombia Bogotá, Arboleda \& Valencia Editores, 1900, p. 4.

${ }^{67}$ URIBE, Antonio José, "La Ley Orgánica. Exposición de motivos", en Instrucción pública. Disposiciones vigentes. Exposición de motivos, Bogotá, Imprenta Nacional, 1927, pp. 36 - 37.

Digitalizado por RED ACADEMICA
} 
tomado por los Estados Nacionales de occidente, los que, dicho sea de paso, tenían una experiencia histórica y cultural muy diferente a la colombiana.

El ideal del desarrollo industrial permeó buena parte de la legislación educativa y la organización misma del sistema escolar, desde el nivel de primaria hasta el profesional, ya que resultaba indispensable en el ambiente de la época superar, "el predominio que tienen entre nosotros los estudios teóricos [...] las abstracciones sobre lo concreto, lo ideal sobre lo real”"68. En esta dirección, la instrucción primaria oficial debería preparar a los niños para asuntos prácticos que permitiese su pronta vinculación al mundo productivo. Así, Antonio José Uribe anotó que, "[...] la instrucción primaria debe simplificarse, a fin de difundirse extensamente; [...] debe tender a preparar a los niños en el ejercicio de la ciudadanía, despertando y avivando en ellos el amor a la Patria; [...] debe, así mismo, tender a prepararlos para la agricultura, la industria fabril y el comercio, y procurar que, por las enseñanzas religiosa y física, se formen caracteres nobles y hombres de energía, sanos y vigorosos" $"$.

En cuanto a la organización del sistema escolar, replanteando lo dispuesto en el decreto 349 de 1892, la instrucción pública quedó dividida, según lo expuesto en la ley 39 de 1903, en cuatro secciones. En primer lugar, se halla la instrucción primaria, dentro de la cual podemos encontrar cuatro tipo de escuelas: las primarias dirigidas por los jefes de las misiones religiosas en territorios en donde éstas hicieran presencia, las escuelas primarias de las intendencias nacionales (alejadas de las regiones centrales del país), las escuelas primarias rurales alternas (de tres años de estudio) y las escuelas urbanas (compuestas por seis años de estudio). En segundo lugar, la ley definió la instrucción secundaria, que a su vez estaba dividida en las siguientes partes: escuelas normales de varones y mujeres (para la formación de maestros), instrucción secundaria técnica y, por último, instrucción secundaria clásica o de filosofía y letras.

La tercera sección se denominó Instrucción Industrial y Técnica y estaba compuesta por la Escuela de Artes y Oficios, el Instituto Agrícola y la Escuela Nacional de Minas. La cuarta sección fue la de Instrucción Profesional, en la cual confluían las Facultades de Filosofía y Letras, Medicina y Ciencias Naturales, Matemáticas e Ingeniería, Derecho y Ciencias Políticas, el Colegio Dental y las Facultades profesionales de los Departamentos. Cada una de las escuelas inscritas en las diferentes secciones definidas por el Ministerio de Instrucción Pública contaba con un plan de estudios específico y respondía a distintos intereses políticos y sociales.

En el ámbito departamental, la ley exigía que los niños fueran formados tanto para el desarrollo de actividades productivas, especialmente la agricultura, como para el ejercicio adecuado de la ciudadanía, teniendo el cuidado de fijar en los menores los deberes y compromisos que tenían en el proceso de construcción de la nación. Para los dirigentes nacionales, las generaciones del siglo XIX se habían encargado de sumir al país en una situación política demasiado inestable, por lo cual, las nuevas generaciones del siglo XX tenían a su cargo la reconstrucción -regeneración- de la nación y la consolidación del orden social. Con respecto a lo anterior, los fines de la instrucción primaria y secundaria, planteados en la Ley 39 de 1903, fueron los siguientes:

Artículo 6. Es obligación de los Gobiernos Departamentales difundir en todo el territorio de su mando la instrucción primaria, reglamentándola de modo que en el menor tiempo posible y de manera esencialmente práctica se enseñen las nociones elementales, principalmente las que habilitan para el

\footnotetext{
${ }^{68}$ Ibíd., p. 4.

69 Ibíd., p. VII. 
ejercicio de la ciudadanía y preparen para el de la agricultura, la industria fabril y el comercio. Artículo 11. La instrucción secundaria será técnica y clásica. La primera comprenderá las nociones indispensables de la cultura general, los idiomas vivos y las materias preparatorias para la instrucción profesional respectiva. La segunda comprenderá todas las enseñanzas de Letras y Filosofía. En los colegios e institutos establecidos oficialmente con rentas nacionales, departamentales o municipales, se dará preferencia a la instrucción técnica ${ }^{70}$.

La orientación hacia la formación técnica a partir de la cual los individuos pudiesen tener rápidas posibilidades de acceso al mercado laboral, también se enfatizó en la educación de las mujeres. En 1908, Pedro Toro anotó lo siguiente: "No pretendo que las mujeres vengan a discutir en las Asambleas populares, ni a pelear en los campos de batalla, ni a oficiar en los altares... Aspiro a que en lo posible estudien ciencias, artes e industrias y adquieran hábitos de trabajo que, sin humillaciones ni afrentas, les alcancen a satisfacer sus necesidades y aun a forjarse fortuna, y que les comuniquen confianza a sus propias fuerzas sin indispensable intervención masculina"71.

Además de tratar de legitimar el orden social existente, haciendo alusión a un principio común sagrado y de promover la formación práctica encaminada a fortalecer la vocación industrial y técnica de los niños, se expuso la necesidad de impregnar el alma del niño de un sentimiento nacionalista y patriótico. Para los dirigentes colombianos la construcción de la nación requería del respeto y la apropiación de los símbolos y los signos patrios que identificaban a Colombia como república independiente. Así, en el decreto 491 de 1904, el cual reglamentó la Ley 39 de 1903, encontramos lo siguiente: "Artículo 58. Los cantos de las escuelas deben también contribuir al cultivo de estos sentimientos. Por tanto los niños cantarán todos los días, al terminar las respectivas tareas, el himno nacional colombiano. Artículo 59. La bandera nacional es por excelencia el símbolo de la Patria y los maestros deben acostumbrar a los niños a saludarla, descubriéndose ante ella como ante una cosa venerable y sagrada"72.

En el camino hacia la construcción de la nación colombiana encontramos un cruce continuo entre lo político y lo religioso. Por un lado, las ideas políticas eran defendidas con un fervor religioso y mesiánico y, por otro, la iconografía patriótica se revestía de un halo sagrado y místico. Estos rasgos son producto, en buena parte, del papel que la institución eclesiástica ha jugado en el campo político. Teniendo en cuenta lo anterior, resulta explicable que se propusiera a los niños descubrirse ante la bandera como ante una "cosa sagrada". Esta intersección entre lo político y lo religioso va a ser una constante, con diferentes matices, en los discursos de las elites nacionales durante toda la primera mitad del siglo XX.

Los fines de la educación, que se fijaban tanto para el nivel primaria como secundaria, apuntaban, entonces, a modelar determinado tipo de ciudadano que cumpliera con tres funciones básicas: servir a Dios, a la patria y a la sociedad. La concepción de ciudadano se ligaba a la de buen cristiano y los valores cívicos se equiparaban a las virtudes definidas por el catolicismo. En este contexto, el servicio a Dios se prestaba mediante el fortalecimiento del espíritu cristiano católico; el deber con la patria se conseguía mediante la creación y consolidación de un sentimiento nacionalista basado en el recuerdo emblemático de los próceres nacionales y los símbolos e iconografía que daban origen a

\footnotetext{
${ }^{70}$ Ley 39 del 26 de octubre de 1903.

${ }^{71}$ TORO URIBE, Pedro, La educación de la mujer, Discurso en el Colegio de Nuestra Señora del Carmen en la sesión solemne de 1907, Facatativa, Imprenta del Departamento, 1908, p. 5.

${ }^{72}$ Decreto 491 del 3 de junio de 1904.
} 
la nación; por último, el servicio a la sociedad estaba relacionado con la capacidad productiva de los individuos $y$, por ende, con las posibilidades que el trabajo brindaba para el desarrollo técnico e industrial de la misma sociedad.

Sin embargo, este modelo formativo se promocionó de manera fragmentada. El énfasis en lo técnico - práctico se hizo, como vimos, en la educación de las clases populares. Con respecto a la idea de Dios, en las clases populares ésta se representaba como la posibilidad de un mañana mejor, mientras que en las elites nacionales el buen cristiano era aquel que practicaba la caridad con el prójimo. En cuanto a la idea de nación, las clases populares nunca se sintieron incluidas en dicho proyecto, a menos que cuando se les enunciaba de manera genérica como el pueblo, entendiendo al mismo como la base de la nación.

\section{El asunto de los planes de estudio en la primera década del siglo $X X$}

Una de las principales preocupaciones de los dirigentes nacionales y los diferentes encargados del Ministerio de Instrucción Pública, posterior Ministerio de Educación Nacional (1926), fue la adopción de un plan de estudios que organizara la enseñanza en los diferentes niveles del sistema educativo nacional. El problema central giró en torno a qué tipo de planes, en cuanto a duración y materias que deberían integrarlos, eran necesarios para las diferentes secciones en que estaba dividida le enseñanza.

En lo concerniente a la escuela primaria rural, el plan de estudios, según el decreto 491 de 1904 que reglamentó la Ley 39, incluía la enseñanza de religión, lectura, escritura, aritmética (asignaturas que se veían durante los tres años de duración de la primaria rural), geografía y urbanidad. Con respecto al plan diseñado para las escuelas urbanas se incluyó mayor número de materias dentro de las cuales se pueden encontrar las siguientes: instrucción religiosa, lectura, lecciones objetivas, aritmética, escritura, dibujo lineal, canto, calisténica, obras de mano, geografía, historia patria, historia natural, gimnasia, entre otras ${ }^{73}$. Es importante anotar que las escuelas para niños se diferenciaron de las destinadas a la educación de las niñas, ya que ellas verían todas las materias mencionadas, con menor intensidad horaria, y además estudiaban materias como costura y economía doméstica ${ }^{74}$.

Sobre la educación secundaria, recordemos que ésta se dividía en escuelas normales, técnica y clásica. Con respecto a la educación secundaria técnica, el decreto 491 de 1904 dispuso que las materias correspondientes a su plan de estudios serían las siguientes: religión, gramática castellana, traducción de inglés y francés, geografía física, aritmética, álgebra, geometría, trigonometría rectilínea, física, química general, cosmografía, lógica y dibujo lineal. Según el decreto, "los alumnos que hubieren hecho estos cursos podrán solicitar que se les expida el grado de bachiller en ciencias, indispensable para ingresar a la facultad de Matemáticas"75.

Anotemos que, a la luz de la legislación educativa de las primeras décadas del siglo XX, la educación secundaria técnica no recibió la misma atención que la clásica, la cual fue reglamentada, además del decreto 491 de 1904, por el decreto 229 del siguiente año. Recordemos que los egresados del bachillerato clásico obtendrían el título de bachilleres

\footnotetext{
${ }^{73}$ Decreto 491 de 1904.

${ }^{74}$ Artículo 68, Decreto 491 de 1904. Tomado de: Instrucción pública. Disposiciones vigentes. Exposición de motivos, op. cit.

${ }^{75}$ Artículo 118, Decreto 491 de 1904. Tomado de: Instrucción pública. Disposiciones vigentes. Exposición de motivos, op. cit
}

Digitalizado por RED ACADEMICA 
en filosofía y letras y tendrían una mayor opción para ingresar a otras facultades universitarias además de la facultad de Matemáticas.

En esta parte resulta de interés mencionar que, posiblemente, los estudiantes del bachillerato técnico optarían por continuar sus estudios en el nivel de instrucción industrial (en el cual se ubicaban la Escuela de Artes y Oficios, el Instituto Agrícola y la Escuela Nacional de Minas) antes que en el profesional. Por su parte, los egresados del bachillerato clásico no tendrían cabida en este nivel de instrucción industrial, sino que obtenían sus cupos, directamente, para el nivel profesional. Lo anterior nos puede dar una idea de la manera en que se distribuía, parafraseando a Bourdieu, el capital escolar y cultural mediante el sistema educativo durante las primeras décadas del siglo XX.

En la reforma del plan de estudios para el bachillerato clásico, dispuesta por el decreto 229 del 28 de febrero de 1905, las materias se organizaron en los siguientes grupos temáticos: instrucción religiosa, gramática, historia y geografía, ciencias matemáticas, ciencias físicas y filosofía. Podemos ver en este plan un primer intento por agrupar la enseñanza de la historia y la geografía, que comprendían los siguientes estudios: formación del globo, tierras, mares, países de la Tierra, mares, principales ciudades, gobierno, religiones, costumbres, razas y lenguas, historia antigua, historia moderna e historia y geografía de Colombia.

Sobre las Escuelas Normales podemos anotar que revistieron una singular importancia en el entendido que sus egresados serían los encargados de instruir a los niños de las escuelas primarias. Por tal motivo, los maestros que se formaran en las Escuelas Normales deberían ser portadores de todos los atributos requeridos para la consolidación de la nacionalidad colombiana y de los principios básicos de la moral católica. Además de instruir a los niños en estos aspectos, los maestros deberían ser un ejemplo a seguir para los estudiantes de las escuelas primarias. Con respecto a los estudios que se seguirían en las Escuelas Normales, además de las asignaturas que se cursaban en el bachillerato clásico, se incluían otras como: instituciones constitucionales y administrativas del país y de la legislación sobre instrucción pública primaria, pedagogía y metodología (teórica y práctica), idioma nacional (lectura, gramática, ortografía, ejercicios de redacción y locución), las cuales se consideraban como soporte básico en la formación como normalistas ${ }^{76}$.

En cuanto a la enseñanza de la historia para todos los niveles de enseñanza, podemos anotar que la conmemoración de los primeros cien años de las gestas independentistas contribuyó a reavivar y redimir el sentimiento de nacionalidad que, quizás, había sido fracturado por las guerras civiles del siglo XIX. Nuevamente, como ocurrió desde inicios de la época republicana en el siglo XIX, se hizo énfasis en el papel que la educación debía jugar en la consolidación de un proyecto de nación y en el fortalecimiento de la nacionalidad. Durante las primeras décadas del siglo XX, otro elemento interesante fue el modelo pedagógico definido por el gobierno nacional y por las directivas del Ministerio de Instrucción Pública. En este aspecto, Antonio José Uribe anotaba que toda enseñanza debía darse según el método intuitivo y práctico, tratando de que las lecciones de cosas no fueran tanto lecciones como sí cosas. En el referido decreto 491 de 1904 se anotó lo siguiente, con respecto al método de enseñanza que debía ser utilizado por los maestros:

Las instituciones deben basar sus enseñanzas, en cuanto sea posible, sobre la intuición; teniendo cuidado de despertar constantemente en los alumnos el espíritu de observación, de reflexión y de

\footnotetext{
${ }^{76}$ Decreto 491 de 1904, Tomado de: Instrucción pública. Disposiciones vigentes. Exposición de motivos, op. cit. 
invención, y de acostumbrarlos a expresar sencilla pero correctamente sus propias observaciones, sus propios raciocinios. Las nociones que se inculquen deben ser siempre exactas y se debe tener presente que las repeticiones hechas bajo formas variadas y atractivas hacen familiares las materias enseñadas ${ }^{77}$.

Con respecto a la enseñanza de la historia también se encuentra un interés pragmático: aprender los hechos del pasado para no repetirlos en el presente. Así en las memorias del citado ministro se anota que, "[...] debe estudiarse no como acumulación de nombres propios, fechas y acontecimientos, sino como sucesión de causas y efectos; [ya que] si para algo hay que volver la cara al pasado, no es para el discutir y el lamentar infecundos, sino para sacar lecciones en el porvenir: esto indica que nos convendrá enseñar de preferencia la historia de los errores nacionales, para corregirlos en lo futuro" $^{\prime 7}$. En esta perspectiva, se puede notar que la enseñanza de la historia, en la primera década del siglo XX, obedeció a la necesidad de reafirmar los valores de la patria, fracturados por las guerras del siglo XIX, mediante el enaltecimiento de símbolos y próceres nacionales.

Además de la figura y el oficio del maestro, el conocimiento escolar se produjo y transmitió a través de otras vías como lo son los textos escolares, sobre los cuales se hizo énfasis en la necesidad de que los inspectores de educación mantuvieran un control sobre la producción, publicación y distribución de los mismos. Mediante los textos escolares se difundía el ideario propio de la nación colombiana y su método de enseñanza contribuía a la formación de espíritus nacionalistas, productivos y respetuosos de la moral católica, a la cual se encomendó la educación desde la reforma constitucional de 1886 y la firma del Concordato con la Santa Sede en 1887. Para Fernán González,

\begin{abstract}
El Concordato es una consecuencia lógica de lo estatuido por la Constitución. Joaquín Fernando Vélez había sido nombrado representante del gobierno de José Eusebio Otálora ante la Santa Sede, pero sin instrucciones. Vélez regresa al país para participar en la defensa del gobierno de Núñez en la guerra civil (1885) y es nuevamente nombrado como enviado extraordinario y ministro plenipotenciario ante la Santa Sede, con instrucciones de puño y letra de Núñez. Según éstas el convenio debe reflejar fielmente el espíritu de la Constitución; el reconocimiento de la deuda debe enmarcarse teniendo en cuenta la penuria fiscal del gobierno, que sólo puede cumplir compromisos muy módicos; en compensación, el gobierno ofrece auxilios presupuestales para misiones, seminarios y diócesis pobres (...) reconoce efectos civiles a los matrimonios canónicos reservándose la soberanía del gobierno en los demás. Los obispos señalarían los textos de religión para los colegios nacionales y el gobierno intervendría para que los textos de otras materias no estuvieran en desacuerdo con la doctrina católica ${ }^{79}$.
\end{abstract}

Es importante resaltar que la publicación de los textos oficiales que serían utilizados en las escuelas públicas primaria y secundaria, requerían del visto bueno de las autoridades eclesiásticas y civiles. En torno a ello, en el decreto 491 de 1904 se dispuso lo siguiente: "los textos que se elijan para la enseñanza de materias morales y religiosas deberán ser aprobados previamente por el llustrísimo señor Arzobispo de Bogotá, con arreglo al Concordato"80. Así mismo, en los textos de historia también era necesaria la aprobación de las autoridades religiosas del país, pues se concebía que con esta disciplina se construía el alma nacional. Con respecto a ello, se anotó desde el Ministerio una falta de uniformidad que contribuyera a fortalecer un sentimiento nacionalista en los niños ${ }^{81}$.

\footnotetext{
${ }_{78}^{77}$ Artículo 54, Decreto 491 del 3 de junio de 1904.

${ }^{78}$ Ibíd., p. 9.

${ }^{79}$ GONZÁLEZ, Fernán, Poderes enfrentados. Iglesia y Estado en Colombia, Bogotá, Cinep, 1997, p. 256.

${ }^{80}$ Artículo 73, Decreto 491 del 3 de junio de 1904.

${ }^{81}$ ZAPATA, Ramón, Política instruccionista, Bogotá, Imprenta Nacional, 1927. 
A fin de remediar tan grave mal, se ha creado recientemente una Junta de Institutores ilustrados encargada de formar los programas de enseñanza para las escuelas públicas y para las escuelas normales. Aprobados que sean tales programas por el Ministerio, se insertarán en el Diario Oficial, a fin de que, dentro del plazo de ocho meses, puedan presentarle al Ministerio los textos que, en desarrollo de tales programas, escriban los autores que acepten el concurso que habrá de abrirse al efecto. Los textos que se reciban en el Ministerio serán apreciados por un Jurado calificador y los que éste indique se adoptarán para la enseñanza en los establecimientos públicos de instrucción primaria y secundaria ${ }^{82}$.

Vemos, entonces, que con el fin de que los textos seleccionados estuvieran en correspondencia con los fines sociales de la educación planteados por el gobierno y, en general, con las propuestas político - pedagógicas de las elites, se conformó, de acuerdo al artículo 72 del decreto 491 de 1904, una "Junta de pedagogos distinguidos" ${ }^{\text {, }}$, encargados de diseñar los programas que cada maestro debería desarrollar en las distintas materias y se realizarían convocatorias para la elaboración de los textos a utilizar. Valga decir, que en la convocatoria abierta para este efecto en 1908, el texto ganador para la enseñanza de la historia fue el de Henao y Arrubla, al que haremos mención más adelante.

No obstante, a pesar de los posibles esfuerzos en materia de reglamentar y fortalecer la producción de textos escolares por parte del gobierno nacional, las existencias de los mismos en el Ministerio de Instrucción Pública son escasas frente a la demanda de las escuelas del país. Los presupuestos dedicados por el gobierno central para la adquisición y distribución de útiles y textos, nunca fueron suficientes para cubrir la demanda de los mismos en el ámbito nacional. Con respecto a ello se anotó que "a medida que ha venido acentuándose la crisis fiscal, el Gobierno ha sido por necesidad más parco en la compra y repartición de útiles y textos a las escuelas primarias de la República, a pesar de que son constantes las solicitudes que de todo el país se hacen, y que es muy penoso no atenderlas sino en pequeña parte. El material de [las] escuelas disminuye, en tanto que

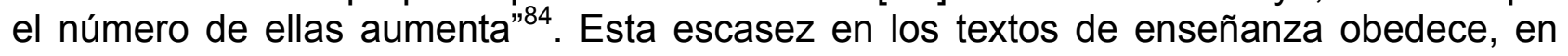
gran parte, a los bajos presupuestos asignados para el Ministerio, lo que impedía tanto una adecuada producción como distribución de los diferentes materiales.

En todo caso, a pesar de los controles sobre la producción de los textos escolares y de las limitaciones en torno a su circulación, podemos indicar que estos materiales se constituyen en un escenario importante para analizar la memoria histórica del país. Es decir, al convertirse en mecanismos de selección de los saberes y, particularmente para la historia, de los hechos que debían ser narrados a los niños, los textos escolares se convierten en un dispositivos cultural de singular importancia para analizar los procesos de conformación de la gramática nacional. Como lo sugiere Agustín Escolano, las imágenes y las ideas expuestas en los textos escolares son "simulacros de la memoria social de una comunidad que transmiten de forma intuitiva el currículum explícito y oculto que el sistema promueve, acepta o tolera". Debido, entonces, al papel de los textos escolares en la narración de la nación, a continuación haremos referencia al caso específico del texto Compendio de historia de Colombia, publicado en 1911 y reeditado varias veces hasta la década de 1960.

\footnotetext{
82 Informe que el Ministro de Instrucción Pública presenta al Congreso de Colombia en sus sesiones ordinarias de 1904, Bogotá, Imprenta Nacional, 1904, p. VIII.

${ }^{83}$ De acuerdo a la Resolución Número 176 del 30 de marzo de 1904, la Junta de pedagogos distinguidos se integró por: Diego Rafael de Guzmán (rector del Colegio de Nuestra Señora del Rosario), dos profesores de la Escuela Normal, Martín Restrepo Mejía y Martín Aguer Bahrendy (Director de la Escuela Modelo).

${ }^{84}$ Memorias del Ministro de Instrucción Pública al Congreso de 1918, Bogotá, Imprenta Nacional, 1918, p. 38.
} 


\title{
3. Memoria e identidad nacional en el texto de Henao y Arrubla
}

Gerardo Arrubla, bogotano, es heredero intelectual del último cuarto del siglo XX (nace en 1872). Bisnieto de el prócer antioqueño José María Arrubla, Gerardo Arrubla se articula al ideal del intelectual de finales del siglo XIX destacándose como abogado (graduado de la Universidad Nacional en 1895), periodista (como director de los periódicos El Correo Nacional y La Opinión) y funcionario en algunos cargos públicos como Alcalde de Bogotá, director de la Biblioteca y el Museo Nacional y director de Instrucción Pública. Para el año de 1908 fue integrado a la Academia Colombiana de Historia, la cual presidió entre 1923 - 1924 y, posteriormente, nombrado como miembro de la Sociedad de Americanistas de París. Por su parte, Jesús María Henao (1870), antioqueño, también se destacó como jurista, graduado del Colegio Mayor de Nuestra Señora del Rosario y de la Universidad Nacional. Su profesión le valió para desempeñarse como juez y fiscal de distintos distritos judiciales de Bogotá. Fue elegido miembro de la Academia Colombiana de Historia en 1909 y estuvo al frente de su presidencia, entre $1914-1915$.

Las breves referencias biográficas anteriores, permiten ver que el perfil académico y profesional de los dos autores es semejante. Abogados y herederos de la tradición ideológica del período de la Regeneración, hicieron de las ideas conservadoras su fuente principal de inspiración. En esta perspectiva, estos dos intelectuales se articulan al estilo de intelectual característico de las primeras décadas del siglo $X X$, encargado de construir un régimen de verdad que legitimara el proyecto naciente del Estado nación, tomando como referentes principales para tal fin los propuestos por la Iglesia católica y, de una u otra manera, los principios del hispanismo. En palabras de Miguel Ángel Urrego,

\begin{abstract}
El tipo de intelectual predominante en esta etapa histórica [principios de siglo] fue la tríada conformada por el gramático, el poeta y el abogado, quienes, eso sí, debían ser católicos y conservadores. No obstante, el campo cultural no es monolítico, y por ello vemos que en ninguna época ha tenido el intelectual una sola función ni tampoco ha habido un solo tipo de intelectual, aunque evidentemente hay formas que predominan [...] Este tipo de intelectual actuó bajo un régimen productor de verdad y tenía la tarea de legitimar el proyecto de Estado nacional conservador, se proyectó en una relación específica con el entorno nacional e internacional y se presentó como permanentemente actualizado, pero, paradójicamente, su reflexión era pobre debido a que no enfrentó críticamente las limitantes sociales, políticas y académicas ${ }^{85}$.
\end{abstract}

Teniendo en cuenta el referente ideológico - político desde el cual escriben Henao y Arrubla, a continuación haremos referencia a las imágenes referidas a la identidad nacional y las concepciones de ciudadanía promovidas en su Compendio de Historia ${ }^{86}$, sobre el cual hay que agregar que se adoptó como texto oficial para la enseñanza de la historia en las escuelas primarias de todo el país, en 1910, mediante decreto 963, siendo Ministro de Instrucción Pública, Pedro M. Carreño, después de salir ganador de un concurso que para dicho efecto abrió la dirección de Instrucción Pública, en 1908, como conmemoración del centenario de las gestas independentistas. Antes de adentrarnos en este análisis, hagamos una breve descripción de la estructura del texto.

En primer lugar, anotemos que además de la aprobación como texto oficial decretada por el Ministerio de Instrucción Pública se encuentra una aprobación por parte del arzobispado de Bogotá, mediante la cual se da a entender que no existen en el texto elementos contrarios a la doctrina católica. Este dispositivo se convierte en una de las

\footnotetext{
${ }^{85}$ URREGO, Miguel Ángel, Intelectuales, Estado y Nación en Colombia. De la guerra de los Mil Días a la Constitución de 1991, Bogotá, Siglo del Hombre Editores, Universidad Central - DIUC -, 2002, p. 38.

${ }^{86}$ HENAO, Jesús María y ARRUBLA, Gerardo, Compendio de la Historia de Colombia para la enseñanza en las escuelas primarias de la República, Bogotá, Imprenta Eléctrica, 1911.
} 
estrategias de control dispuestas para proteger el régimen de verdad propuesto por los dirigentes políticos y eclesiásticos.

En segunda instancia, en la estructura temática del texto se evidencia una mayor dedicación a la república (periodizada entre 1819 - 1910) en donde se mencionan los presidentes que ocuparon el cargo a lo largo del siglo XIX. Los temas que siguen en orden de importancia son la independencia y la colonia, quedando rezagado a unas muy breves referencias iniciales el tema del origen de los pueblos americanos y la época precolombina. Sobre este punto, es conveniente anotar que el rasgo hispanista y europeizante de Henao y Arrubla se evidencia en sus continuos reconocimientos a los españoles, y en general a los europeos, en el 'proceso civilizatorio' colombiano. En torno a la imagen de los europeos se ve lo siguiente en el texto: "los colombianos procuraban la venida de extranjeros para alcanzar el adelanto del país, y las costumbres inglesas estaban muy a la moda. Estableciéronse en Bogotá carreras de caballos, como en Inglaterra, en las cuales se hacían muchas apuestas de dinero; y en las escuelas y oficinas públicas se empezó a usar la escritura de forma inglesa en lugar de la española"87.

Lo anterior nos pone en frente de un tema interesante que enunciamos con anterioridad, cual es el papel del texto escolar en la construcción de la memoria histórica y social. Como lo sugiere Todorov, la memoria es forzosamente una selección; es decir, algunos rasgos del pasado serán recuperados en el presente para constituir la memoria, dependiendo de los intereses de quien haga dicha recuperación y de los planes de presente que se tenga. Para Todorov, "la recuperación del pasado es indispensable; lo cual no significa que el pasado deba regir el presente, sino que, al contrario, éste hará del pasado el uso que prefiera" ${ }^{88}$. En esta perspectiva, lo que nos están expresando las ideas del texto de Henao y Arrubla son los proyectos específicos en torno a la ciudadanía y a la nación colombiana que tenían los sectores dirigentes. Así, al monopolizar el derecho a la producción de sentido sobre la realidad nacional, las elites hicieron como suyo el proyecto de construcción nacional dándole al mismo las orientaciones que les parecieran convenientes. En el caso del texto de Henao y Arrubla, el silencio (la selección) sobre buena parte de la historia indígena pone de manifiesto el perfil del proyecto político que se tenía en mente: al estilo europeo occidental.

Es conveniente tener en cuenta que la consolidación del proyecto de Estado nación a principios del siglo XX, requirió del concurso de diversas estrategias, políticas, sociales, económicas, culturales y educativas, dentro de las cuales el estudio y enseñanza de la historia fue un medio fundamental; de allí que Henao y Arrubla sugieran en el texto que "así como la patria debe ser objeto de nuestro tierno afecto, su historia tiene que serlo de nuestros primeros estudios, porque ella nos ofrece altas lecciones morales y cívicas y fortifica en nuestros corazones el sentimiento del bien y el amor al deber" ${ }^{\prime 2}$. En torno a ello, Miguel Ángel Urrego anota lo siguiente:

La reflexión histórica fue un medio privilegiado para las opciones políticas y los intelectuales que difundían su visión del mundo y la cultura. No en vano la Academia Colombiana de Historia se fundó bajo la Hegemonía Conservadora. Como era de esperarse, el pasado colonial fue un tema privilegiado. Los discursos en los cuales la obra de la conquista aparecía como una labor titánica, posible sólo por el aliento de la Providencia, emergieron nuevamente. De manera que los actos de celebración se caracterizaron, generalmente, por ser actividades apologéticas que resaltaban la

\footnotetext{
${ }^{87}$ Ibíd., p. 135.

${ }^{88}$ TODOROV, Tzvetan, Los abusos de la memoria, Barcelona, Paidós, 2000, p. 25.

${ }^{89}$ HENAO, J. y ARRUBLA, G., op. cit., p. 7.

Digitalizado por RED ACADEMICA
} 
importancia de la tradición, el idioma, y, por supuesto, la religión, todo dentro de una evidente felicidad por hacer parte de una raza de origen español ${ }^{90}$.

De acuerdo al énfasis que se hace en el texto de Henao y Arrubla sobre los elementos que definen la identidad nacional, podemos agruparlos en referentes para la construcción de la misma. En primer lugar, encontraríamos unos imaginarios de la identidad nacional naturalizados; es decir, al concebir a la república independiente como la nueva madre patria, se podría -e incluso, se debía- dar la vida por ella. En nombre de la relación filial, naturalizada, de la identidad nacional se podría entregar hasta la muerte: “ ¡Cuán hermoso es morir así por la patria, por más terrible que parezca el modo como rindieron su vida nuestros Próceres! El sacrificio de la vida por ella es uno de menores [sic] que debemos hacerle" ${ }^{\prime 1}$.

Como lo sugiere Hans-Joachim König ${ }^{92}$, en la tarea de consolidar el nacionalismo se emplearon diversas metáforas a partir de las cuales movilizar las emociones de la población y reunirlas en torno a intereses comunes. Dentro de tales metáforas, entonces, la del amor filial cobra bastante importancia ya que el hogar, la familia, empieza a simbolizarse como la base de la sociedad. En esta perspectiva, Henao y Arrubla anotan que "a semejanza de nuestros mayores, seremos como leones para vencer o morir cuando la Patria nos pida en su defensa la vida y todo. Es buen ciudadano el que conoce, ama y cumple sus deberes; honra la santidad de la Religión y del hogar; respeta y obedece a la legitima autoridad; quiere más el bien público que el suyo propio, y aspira siempre al honor y al engrandecimiento de la Patria"93.

Un segundo tipo de imaginarios sobre la identidad estaría en relación más estrecha con la figura de los próceres nacionales como fuente de inspiración para la república. En esta dirección, la importancia de la identidad nacional no radica tanto en el sentimiento filial con la imagen de la nación, sino con los artífices de la misma. Producto de la influencia de la historiografía política apologética de la Academia Colombiana de Historia, Henao y Arrubla colocan en el centro de los estandartes de la nacionalidad a la épica de los grandes héroes. Veamos un ejemplo de esta versión apologética:

Aquella espléndida demostración pública de un pueblo agradecido por los heroicos servicios hechos en su bien no debe recogerse en nuestra historia como un simple acontecimiento del pasado que no deja huella profunda en los sentimientos delicados del hombre. Si contemplamos con admiración, y aplaudimos muchos de los extraordinarios hechos ejecutados en la epopeya que se llama la Conquista, la admiración y gratitud han de ser eternas para nuestros libertadores; y cuando nos venga a la memoria el recuerdo de la sangre derramada en los cadalsos, de los sufrimientos de las viudas y de los huérfanos, de los peligros sin segundo arrostrados a costa de todo por los guerreros de la Independencia, debemos sentir en nuestros pechos tanto entusiasmo y amor como el que experimentaron los hijos de Santa fe al recibir a los héroes de Boyacá con los honores del triunfo ${ }^{94}$.

Sobre esta apología a los héroes nacionales, podemos ver cómo en la selección de referentes históricos realizada por Henao y Arrubla para fortalecer la memoria nacional, se privilegia al hombre - mito; es decir, se construye una imagen mítica, sagrada, de los héroes que los hace trascender a una esfera imaginaria. Superando incluso la misma muerte, los héroes magnificados y sacralizados se convierten en referentes de primer orden para la construcción de la memoria nacional. Siguiendo algunas alusiones de Marx

\footnotetext{
${ }^{90}$ URREGO, Miguel Ángel, op. cit., p. 50.

${ }^{91}$ HENAO, J. y ARRUBLA, G., op. cit., p. 108.

92 KÖNIG, Hans - Joachim, En el camino hacia la nación. Nacionalismo en el proceso de formación del Estado y de la Nación de la Nueva Granada, 1750 - 1856, Bogotá, Banco de la República, 1994.

93 Ibíd., p. 188.

${ }^{94}$ Ibíd., p. 121. 
en El dieciocho brumario de Luis Bonaparte, Bernardo Tovar sugiere que esta 'resurrección de los muertos' tiene unos intereses específicos relacionados con los atributos que deben tener los ciudadanos del presente para enaltecer la patria. Para este autor, "en el goce la victoria primigenia rememorada se producía una participación de la comunidad que permitía renovar o restaurar el equilibrio y la cohesión social. De cierta manera, estas fiestas pueden verse también como un culto a los muertos, en tanto que en ellas los vivos renuevan su relación de identidad con los antepasados políticos, con los héroes primigenios de la nación, actualizan el mensaje de éstos y aseguran su continuidad en el tiempo"

El tercer referente para construir los imaginarios sobre la identidad nacional es el asunto religioso. Como bien sabemos, la historia política de nuestro país ha estado ligada, permanentemente, a la historia eclesiástica y de allí se desprende que haya un continuo cruce entre la iconografía religiosa y la iconografía cívica. Este hecho a fortalecido, entre otros aspectos, el carácter intolerante, excluyente y polarizado de nuestra cultura política. Como anota Fabio López,

El hecho que la religión se convirtiese desde mediados del siglo XIX en la frontera divisoria entre los partidos liberal y conservador, le confirió a la contienda política en Colombia un fuerte carácter sectario e intolerante. En el imaginario político de los colombianos se volvió un lugar común el asociar a los liberales como 'rojos', 'ateos', 'librepensadores', 'masones', 'comecuras', y a los conservadores como 'godos', 'rezanderos', 'beatos' o 'camanduleros'. Los partidos políticos 'civiles' utilizaron deliberadamente durante décadas esos imaginarios políticos asociados a la pertenencia religiosa, para aumentar su caudal electoral ${ }^{96}$.

Al entrar al universo religioso, la idea política se convierte en dogma y la creencia en ella se transforma en fe; es decir, la idea política empieza a vivirse como algo sustantivo de la moralidad de los sujetos y de allí el fervor con el que se le defiende. Para el caso del texto de Henao y Arrubla, la promoción de las ideas del catolicismo como fuentes de la nacionalidad colombiana arrasa, incluso, con la imaginería religiosa tradicional de los indígenas, sobre la cual encontramos la siguiente referencia: "La falsa religión tenía prácticas muy crueles, pues los jeques o sacerdotes sacrificaban a los ídolos víctimas humanas, particularmente niños"97.

En frente de esta idea salvaje, incivilizada, de los pasados aborígenes, se contrapone la figura virtuosa, abnegada y transparente, del misionero y el cura, cuyo fin era salvar las almas de los infieles pueblos indígenas. Para Henao y Arrubla, "desde que comenzó la conquista, esos apóstoles de Jesucristo, con abnegación sin límites, predicaron el evangelio a los salvajes, y al propio tiempo que alumbraron sus entendimientos con la luz de la verdad religiosa, por medio de la suavidad y de la paciencia les inculcaban las costumbres de la vida civilizada" ${ }^{98}$. Podríamos sugerir que estas alusiones de los autores están en relación con el proyecto español desde la época de la conquista mediante el cual se intentaba imponer el "imperio de Cristo", como fuente de legitimidad de la autoridad civil $^{99}$.

\footnotetext{
95 TOVAR ZAMBRANO, Bernardo, "Porque los muertos mandan. El imaginario patriótico de la historia colombiana", en C. Ortiz y B. Tovar (editores) Pensar el pasado, Bogotá, Universidad Nacional, Archivo General de la Nación, 1997, p. 147.

${ }_{96}$ LÓPEZ DE LA ROCHE, Fabio, "Tradiciones de cultura política en el siglo XX", en M. Cárdenas (Coordinador) Modernidad y sociedad política en Colombia, Bogotá, Fescol, lepri, Ediciones Foro, 1993, pp. $106-107$.

${ }_{97}^{97}$ HENAO, J. y ARRUBLA, G., op. cit., p. 40.

${ }^{98}$ Ibíd., p. 41.

99 DRI, Rubén, "Teología de la Dominación y Conquista", en H. Dieterich (editor) 1492 - 1992 La interminable Conquista, Bogotá, Editorial El Búho, 1991.
} 
Un cuarto referente en la definición de la nacionalidad en el texto de Henao y Arrubla tiene que ver con el sentimiento de gratitud e identificación que se propone con respecto a España. Así, a pesar de elogiar las gestas independentistas y recabar en los héroes nacionales como figuras que aglutinan el sentimiento nacional, en el fondo subyace una añoranza por los valores del hispanismo -las buenas costumbres, la mística, los valores religiosos, etc.-, los cuales se proponen emular. Esta situación de tener como referente a España y al viejo continente en la construcción del imaginario nacional, es referida por Frédéric Martínez de la siguiente manera:

A la hora de crear naciones, hay una necesidad de modelos. En la Hispanoamérica decimonónica, esos modelos son ante todo europeos. Si bien la ruptura del vínculo político con Europa se consuma con la Independencia, la ruptura del vínculo de identidad apenas comienza: se dará lentamente en el transcurso del siglo XIX. La brusquedad de la Independencia política contrasta con la lentitud del proceso de distanciamiento de las identidades. El universo de referencia de los nuevos dirigentes, en cuyas manos está la construcción de las nuevas naciones, sigue siendo europeo, y el postulado de la autoridad europea, por más que sea permanentemente cuestionado en la efervescencia del debate público, constituye todavía el telón de fondo del imaginario político hispanoamericano. El sentimiento colonial de los criollos, quienes mucho después de la Independencia continúan percibiéndose como europeos de ultramar -la identificación por un origen europeo que los distingue de la plebe tiene prelación sobre una identificación por la nacionalidad- contribuye a mantener viva, por largo tiempo, la autoridad de Europa ${ }^{100}$.

La gratitud frente a los españoles en el texto de Henao y Arrubla se expresa de diversas formas, y una de ellas es reconocer su labor en el proceso de la civilización de las tribus indígenas en el período de la colonia. Veamos: "No debemos, pues, maldecir esta conquista, porque gracias a ella vino a nuestra tierra la civilización europea, y le debemos el tesoro inestimable de la verdadera religión y el hermoso idioma que hablamos" ${ }^{101}$. Así mismo, se utilizaban los datos de la historia con el fin de dejar en evidencia el supuesto hispanismo que había permanecido en el sentir de los próceres nacionales. En torno a ello se sugiere que: "el movimiento grandioso y fecundo de la revolución del 20 de julio quedó consignado en un acta, en que se reconocía como monarca del Nuevo Reino al de España, Fernando VII, siempre que viniera a Santa fe a gobernar"102.

En general, las apreciaciones encontradas en el texto de Henao y Arrubla, relacionadas con la identidad nacional y el ideal de ciudadanos para la naciente república, se corresponde con el espíritu de la época en torno a las virtudes y atributos que eran propios de un ciudadano. Ana María Toscano, en un estudio presentado al primer Congreso Pedagógico Nacional, realizado en 1917, se refirió a tales atributos de la siguiente forma:

La escuela de primeras letras, en una palabra, a la vez que hacer mantener bueno al niño, debe tender al fin, tan primordial como ese otro, de formar en el niño al ciudadano o a la madre de familia; de hacer de él un miembro útil de la sociedad, a quien la patria puede llamar su hijo con orgullo; y de echar, en fin, los primeros fundamentos de un ser apto efectiva y prácticamente para la vida. Este programa tan sencillo consulta el triple fin de la instrucción primaria con relación a Dios, a la sociedad y al individuo; corresponde a las tres fases que, según algunos pedagogos modernos, debe ella comprender, como son la sugestión de ideales, la inculcación de buenos hábitos y la relativamente secundaria que implica la transmisión de conocimientos científicos del maestro. En la función de sugerir ideales abarca la sugestión del ideal supremo que es Dios; del ideal del Bien y del ideal del hombre bueno y honesto; del ideal de la Patria y del ideal del buen ciudadano y del miembro útil y sano de la sociedad y la familia; del ideal del yo obligado a bastarse a sí propio y a llenar en el

\footnotetext{
${ }^{100}$ MARTÍNEZ, Frédéric, El nacionalismo cosmopolita. La referencia europea en la construcción nacional en Colombia, 1845 - 1900, Bogotá, Banco de la República, Instituto Francés de Estudios Andinos, 2001, p. 531.

${ }_{101}$ HENAO, J. y ARRUBLA, G., op. cit., p. 19.

102 Ibíd., p. 84. 
mundo una visión benéfica de adelantamiento y de progreso en todos los órdenes de la humana actividad $^{103}$.

Vemos aquí una buena síntesis de lo que se esperaba formar en el ciudadano durante los primeros años del siglo XX. Se destacan en esta síntesis elementos como utilidad del ciudadano para la sociedad, fe y respeto por los valores del cristianismo y buenas costumbres. En este sentido, podemos anotar que los elementos que articulan la 'modernidad política' colombiana, a principios del siglo XX, provienen de las fuentes más diversas y se funden en el ideal de ciudadano de acuerdo a las necesidades de las elites nacionales en su tarea de alcanzar determinado tipo de orden social. Este sincretismo ciudadano está marcado por la presencia de ideales pragmáticos -provenientes de la mentalidad ilustrada europea del siglo XVIII y de la posible influencia de vertientes utilitaristas inglesas-, valores de la cristiandad -cuyo origen se encuentra en el espíritu mesiánico de la España medieval- y algunos elementos del ideal de la civilidad, de las buenas maneras, de la sociedad cortesana europea de los siglos que antecedieron a las revoluciones burguesas. Sumado a este último elemento, hay un componente interesante cual es el cuidado y control higiénico del cuerpo como factor de progreso individual y nacional. En torno a este aspecto, Zandra Pedraza anota lo siguiente:

El cuerpo se convirtió en objeto de interés para discursos y prácticas en Colombia, debido al progreso de la biología, la higiene y la crítica situación de salud que el país enfrentaba a comienzos del siglo. Un problema de envergadura era la necesidad imperiosa de aumentar el crecimiento poblacional y la esperanza de vida para crear una fuerza laboral capaz de llevar a cabo la industrialización y el crecimiento económico. Por otro lado, era igualmente necesario crear una elite nacional que dirigiera al país hacia el progreso y la modernización. Esta situación condujo a pedagogos, médicos, gobernantes y humanistas a concentrarse en el cuerpo como el origen de los problemas nacionales y la fuente de su solución ${ }^{104}$.

Podríamos sugerir, entonces, que una de las principales características de nuestra modernidad política y de los proyectos de nación y formación ciudadana de principios del siglo XX, está relacionada con la simbiosis de elementos disímiles, y en algunos casos contradictorios, que fueron apropiados en un contexto marcado por la necesidad de superar, por un lado, las fuertes pugnas políticas e ideológicas dentro de los diversos sectores de las clases dirigentes, y, por otro lado, de acercar a la mayor parte de la población a un imaginario nacional que, durante más de un siglo, había sido construido aislada y paralelamente a su experiencia histórica y colectiva.

\section{Conclusiones}

Como ha sido expuesto en algunos análisis sobre el tema ${ }^{105}$, el papel de los intelectuales en la sociedad no se agota con sus actividades académicas sino que también tiene que ver con las relaciones que entablen con el poder. De acuerdo a lo sugerido por Gramsci $^{106}$, generalmente los intelectuales funcionan como legitimadores de determinado orden social y político sugerido por el Estado y por las clases dirigentes. Sin entrar en disertaciones sobre el papel del intelectual en la sociedad colombiana actual, señalemos

\footnotetext{
103 TOSCANO, Ana María, La escuela primaria: causas de su deficiencia en Colombia, estudio presentado el Congreso Pedagógico Nacional de 1917, Bogotá, Imprenta Nacional, 1917, p. 6.

${ }^{104}$ PEDRAZA, Sandra, "Sentidos, movimiento y cultivo del cuerpo: política higiénica para la nación", en M. Herrera y C. Díaz (compiladores) Educación y cultura política: Una mirada multidisciplinaria, Bogotá, Universidad Pedagógica Nacional, Plaza \& Janés, 2001, p. 113.

${ }^{105}$ Al respecto ver: BOBBIO, Norberto, La duda y la elección, Barcelona, Paidós, 1998.

${ }^{106}$ GRAMSCI, Antonio, Los intelectuales y la organización de la cultura, Buenos Aires, Ediciones Nueva Visión, 1997.
} 
que en la coyuntura de finales del siglo XIX y principios del XX, el modelo de intelectual (el gramático, el poeta y el abogado) está en estrecha relación con el proyecto político de las elites dirigentes, de allí que Urrego identifique esta etapa de la historia de los intelectuales como "intelectuales orgánicos del bipartidismo". Para Gonzalo Sánchez, las actividades de los intelectuales en esta coyuntura contribuyeron a fortalecer un proyecto específico de las elites nacionales, al cual se refiere de la siguiente forma:

La crisis del discurso liberal radical y anticolonialista (Florentino González, José María Samper), de buena parte de la segunda mitad del siglo XIX, 'con su ética ciudadana y democrática', le abría el paso a una verdadera transición regresiva, que se manifestaba en el intento de refundar la nación a partir de la cultura hispánica. Fue un intento en gran medida exitoso que podría catalogarse con toda propiedad como el contragolpe cultural de la Regeneración. Parafraseando a Núñez pudiera decirse que el nuevo movimiento político - cultural sometía la república laica y positivista a la tutela de la república espiritual y neotomista que pregonaba el obispo Rafael María Carrasquilla, Secretario de Instrucción Pública del Presidente Miguel Antonio Caro. Era el regreso a una visión tiránica y homogeneizadora de la cultura y de la sociedad ${ }^{107}$.

Para el caso analizado en este documento, podemos anotar que el texto de Henao y Arrubla, intelectuales formados en el ideario político de la Regeneración, se articula a los intereses del proyecto político de las elites a principios de siglo tendiente a imponer un orden social caracterizado por elementos como: retorno a concepciones medievales sobre subordinación del poder temporal al poder espiritual, la Iglesia como elemento cohesionador de la sociedad, la supeditación de la ley a la moral y el cambio del ciudadano burgués (inspirado en la revolución francesa) al ciudadano católico virtuoso ${ }^{108}$.

En este proceso de legitimación del orden social anclado en los soportes de la Regeneración, Henao y Arrubla seleccionaron determinados elementos políticos y culturales de la historia nacional para difundir en su Compendio de historia, selección que apuntaba a la [re] elaboración de una propuesta específica de memoria nacional. En esta perspectiva, no se recuperan con la misma intensidad las tradiciones indígenas, negras, o las costumbres de los criollos 'no ilustrados', como fuente de la identidad nacional, privilegiando para tal fin los valores, imágenes y referentes europeos -principalmente de los españoles y los ingleses.

Teniendo en cuenta la propuesta de David Miller ${ }^{109}$, para quien la nacionalidad tiene que ver con cuatro tipo de registros (fronteras, soberanía, identificación del ciudadano con el Estado y política interna del Estado), la identidad propuesta en el texto de Henao y Arrubla se alejaría de tales referentes. En este último caso, como vimos, se identificaron cuatro registros para promover la identidad y la memoria nacional: referente filial / sentimental con la nueva nación, figura de los próceres nacionales, parámetros del catolicismo y, por último, carácter hispanista de la nación colombiana. Estos referentes obedecen a una suerte de sincretismo cívico - religioso en el cual se mezclan elementos de la ciudadanía burguesa europea, del misticismo español y de la 'valentía' de los criollos independentistas. Siguiendo los análisis de Norbert Lechner, para el caso de los países de América Latina en el siglo XIX, podemos anotar que las propuestas de las elites buscaban,

[...] fijar lo que es la historia común y atar la identidad nacional a la memoria de ese pasado común. Se trata de una operación delicada: nada menos que de rehacer la historia con miras a los retos del

\footnotetext{
107 SÁNCHEZ, Gonzalo, "Intelectuales... poder... y cultura nacional", en Análisis Político, № 34, Bogotá, Universidad Nacional, mayo - agosto de 1998, p. 121.

${ }_{108}$ URREGO, Miguel Ángel, Modernización, identidad nacional y cultura política, Bogotá, Universidad Central - DIUC -, Colciencias, 1996 (informe final de investigación).

${ }^{109}$ MILLER, David, Sobre la nacionalidad, Barcelona, Paidós, 1997. 
presente. Construir una historia nacional implica 'limpiarla' de toda encrucijada, eliminar las alternativas y las discontinuidades, retocar las pugnas y tensiones, redefinir los adversarios y los aliados, de modo que la historia sea un avance fluido que, como imagen simétrica, anuncia el progreso infinito del futuro. La 'historia oficial' no se deja establecer por decreto y así las disputas del pasado pueden perdurar hasta el presente ${ }^{110}$.

¿Cómo definir, entonces, un ethos nacional, un modelo de ciudadano que se articulara a los requerimientos de la nación de principios del siglo XX?, ¿cuál sería la ruta más indicada para formular el nosotros que poblara el territorio conquistado? Como se vio, el camino de la salvación estaba indicado por los designios de la Iglesia católica: los buenos cristianos serían buenos ciudadanos. Pero además, era necesario un componente civilista que recordara no sólo los deberes para con Dios, sino también para con la patria. Este componente civilista estaba dado, en buena parte, por los ideales de la ciudadanía burguesa promovidos desde la revolución francesa y por las 'finas costumbres' de los europeos cortesanos. El modelo se completaba al reconocer lo malo de nuestra raza y eliminarlo a través de la oración, la educación y la obediencia.

En la ruta hacia la ciudadanía civilizada de los colombianos, propuesta por Henao y Arrubla en su Compendio de Historia, el reconocimiento del pasado español y europeo resultó más significativo que los referentes criollo, indígena y negro, los cuales, antes que ser recuperados para la memoria, se condenaron al olvido nacional, el cual, dicho sea de paso, también hace parte de la memoria histórica colombiana.

\section{Bibliografía}

BOBBIO, Norberto, La duda y la elección, Barcelona, Paidós, 1998.

Decreto 491 del 3 de junio de 1904.

DRI, Rubén, "Teología de la Dominación y Conquista", en H. Dieterich (editor) 1492 1992 La interminable Conquista, Bogotá, Editorial El Búho, 1991.

GALLEGO CARDONA, Juan, Pensumes colombianos de Enseñanza Secundaria 1887 a 1955, Medellín, s. e., 1955.

GONZÁLEZ MUTIS, Eugenio, La instrucción pública en Colombia, Bogotá, Imprenta Nacional, 1897.

GONZÁLEZ, Fernán, Poderes Enfrentados. Iglesia y Estado en Colombia, Bogotá, Cinep, 1997.

GRAMSCl, Antonio, Los intelectuales y la organización de la cultura, Buenos Aires, Ediciones Nueva Visión, 1997.

HENAO, Jesús María y ARRUBLA, Gerardo, Compendio de la Historia de Colombia para la enseñanza en las escuelas primarias de la República, Bogotá, Imprenta Eléctrica, 1911.

Informe que el Ministro de Instrucción Pública presenta al Congreso de Colombia en sus sesiones ordinarias de 1904, Bogotá, Imprenta Nacional, 1904.

\footnotetext{
${ }^{110}$ LECHNER, Norbert, "Orden y memoria", en G. Sánchez y M. Wills (compiladores) Museo, memoria y nación, Bogotá, Museo Nacional de Colombia, 1999, p. 70.
} 
HERRERA, Martha; PINILLA, Alexis y SUAZA, Luz Marina, "Perspectivas pedagógicas de los textos escolares de ciencias sociales en la primera mitad del siglo XX", en Pedagogía y Saberes, № 17, Bogotá, Universidad Pedagógica Nacional, 2002.

KÖNIG, Hans-Joachim, En el camino hacia la nación. Nacionalismo en el proceso de formación del Estado y de la Nación de la Nueva Granada, 1750 - 1856, Bogotá, Banco de la República, 1994.

LECHNER, Norbert, "Orden y memoria”, en G. Sánchez y M. Wills (compiladores) Museo, memoria y nación, Bogotá, Museo Nacional de Colombia, 1999.

Ley 39 del 26 de octubre de 1903.

LÓPEZ DE LA ROCHE, Fabio, "Tradiciones de cultura política en el siglo XX", en M. Cárdenas (Coordinador) Modernidad y sociedad política en Colombia, Bogotá, Fescol, lepri, Ediciones Foro, 1993.

MARTÍNEZ, Frédéric, El nacionalismo cosmopolita. La referencia europea en la construcción nacional en Colombia, 1845 - 1900, Bogotá, Banco de la República, Instituto Francés de Estudios Andinos, 2001.

Memorias del Ministro de Instrucción Pública al Congreso de 1918, Bogotá, Imprenta Nacional, 1918.

MILLER, David, Sobre la nacionalidad, Barcelona, Paidós, 1997.

PEDRAZA, Sandra, "Sentidos, movimiento y cultivo del cuerpo: política higiénica para la nación”, en M. Herrera y C. Díaz (compiladores) Educación y Cultura política: Una mirada multidisciplinaria, Bogotá, Universidad Pedagógica Nacional, Plaza \& Janés, 2001.

Reglamento para las escuelas primarias, $1^{\circ}$ de enero de 1894.

ROSALES, José Miguel, La reforma de la instrucción primaria oficial en Colombia Bogotá, Arboleda \& Valencia Editores, 1900.

SÁENZ, Javier; SALDARRIAGA, Oscar y OSPINA, Armando, Mirar la infancia: pedagogía, moral y modernidad en Colombia, 1903 - 1946, Bogotá, Colciencias, Ediciones Foro, Ediciones Uniandes, Editorial Universidad de Antioquia, 1997.

SAFFORD, Frank, El ideal de lo práctico, Bogotá, Empresa Editorial Universidad Nacional, El Áncora Editores, 1989.

SÁNCHEZ, Gonzalo, "Intelectuales... poder... y cultura nacional", en Análisis Político, № 34, Bogotá, Universidad Nacional, mayo - agosto de 1998.

SILVA, Renán, "La educación en Colombia". 1880 - 1930", en Nueva Historia de Colombia, Bogotá, Planeta, 1998, tomo IV.

TODOROV, Tzvetan, Los abusos de la memoria, Barcelona, Paidós, 2000.

TORO URIBE, Pedro, La educación de la mujer, Discurso en el Colegio de Nuestra Señora del Carmen en la sesión solemne de 1907, Facatativa, Imprenta del Departamento, 1908. 
TOSCANO, Ana María, La escuela primaria: causas de su deficiencia en Colombia, estudio presentado el Congreso Pedagógico Nacional de 1917, Bogotá, Imprenta Nacional, 1917.

TOVAR ZAMRANO, Bernardo, "Porque los muertos mandan. El imaginario patriótico de la historia colombiana”, en C. Ortiz y B. Tovar (editores) Pensar el pasado, Bogotá, Universidad Nacional, Archivo General de la Nación, 1997.

URIBE, Antonio José, "La Ley Orgánica. Exposición de motivos", en Instrucción pública. Disposiciones vigentes. Exposición de motivos, Bogotá, Imprenta Nacional, 1927.

URREGO, Miguel Ángel, Intelectuales, Estado y nación en Colombia. De la guerra de los Mil Días a la Constitución de 1991, Bogotá, Siglo del Hombre Editores, Universidad Central - DIUC -, 2002.

URREGO, Miguel Ángel, Modernización, identidad nacional y cultura política, Bogotá, Universidad Central - DIUC -, Colciencias, 1996 (informe final de investigación).

ZAPATA, Ramón, Política instruccionista, Bogotá, Imprenta Nacional, 1927. 